thorpe's lecture on ants, with their bidden and unbidden guests, and also by Prof. Sjostedt's narrative of the Swedish expedition to Kilimanjaro. Able communications were also received from Dr. Horn (Berlin), M. Bouvier (Paris), M. Honrath (Budapest), and others.

On August $5 \mathrm{Mr}$. Howlett, of the Agricultural Research Institute at Pusa, India, gave an excellent account, illustrated by numerous photographs, of the work of that most useful institution; and M. Lahille (Buenos Aires) discoursed to an appreciative audience of the progress of economic entomology in the Argentine. The sectional programme also contained, amongst others, contributions from $\mathrm{Dr}$ W. J. Holland (Pittsburg), Mr. H. Skinner (Philadelphia), and Dr. Horn (Berlin); but the chief business of the day consisted in the winding-up address of the president, Prof. Lameere, and the selection of Oxford as the scene of the next International Congress of Entomology, to be held in I912, with Prof. Poulton, F.R.S., as president.

The evening of August 5 was devoted to a banquet at the Taverne Royale, and on August 6 M. Max, Burgomaster of Brussels, entertained the members of the congress at a grand reception in the Hotel de Ville. The exhibition buildings were open to members throughout the whole of the congress, and excursions were organised in the course of the week to the Congo Museum, the Ardennes, the Field of Waterloo, and other places of interest. The Brussels Museum of Natural History was also visited, and its treasures described by members of the staff.

The congress, as a whole, was an undoubted success. Any defect that may have been noticed in the arrangements was probably due to the fact that, this being the first occasion of the kind, there were no precedents to suide those responsible for the administration. Some inconvenience was suffered from the circumstance that the Salle des Fêtes was in request for other purposes, which interfered to an appreciable extent with the scientific business of the general and sectional meetings; for this, however, compensation was found in the varied attractions of the exhibition, free access to which, by the liberality of authorities, was allowed to all members of the congress.

It is satisfactory to be able to record that, of the 292 members, 67 were representatives of the United Kingdom, its colonies and dependencies. The contributions made by our countrymen to the scientific work of the congress may fairly be said to have surpassed in extent and value those of any other nation-a fact which is of good augury for the future of entomological research within the borders of the British Empire.

\section{THE FIFTH INTERNATIONAL CONGRESS OF PHOTOGRAPHY.}

THE International Congresses of Photography, the first of which was held in Paris in 1889 , are arranged at irregular intervals as opportunities offer or necessity renders desirable, that representatives of all countries may meet and discuss questions of general importance. It is hoped by this means to avoid, or at least mitigate, the confusion that results from variations in standards, nomenclature, and methods, especially when such variations are due more to accident than intention.

The fifth congress, which has just been held in Brussels, was well supported, most of the European nations, as well as America, being represented. More than eighty communications were included in the programme, and these were classified into three main sections:-(I) Scientific questions; photochemistry; scientific applications of photography. (2) Technique of photography ; artistic questions : industrial applications of photography. (3) Photographic documentation and archives; bibliography; legislation. The proceedings of the congress will be published in full in the report that will be issued in due time.

Several of the communications were of the nature of reports setting forth the present state of the section of photographic work dealt with. Captain Th. J. Saconney dealt with aërial photo-surveying. E. Deville gave details concerning photo-surveying in Canada, from which we learn that the extent of the region so surveyed is somewhat greater than the combined areas of Holland and Belgium, the most interesting application of the method NO. 2 I 29 , VOL. 84$]$ being its application in defining the frontier between Alaska and Canada, a district of lofty mountains. A commission was given three years to report concerning a frontier of one thousand kilometres in length, and as only the short summer season of each year was available, on account of the climatic conditions, other than a photographic method would have been impossible. A satisfactory map was prepared from the three thousand photographs made. The photographic method of surveying employed in Canada is eminently practical, not excluding other methods, so that it should be understood merely that photography plays the most important part in it.

Prof. Wilder D. Bancroft contributed a long report on the photographic emulsion, and from the facts that he has set in due order concludes that the silver bromide grain is a complex of silver bromide, gelatine, and water, and that " the process of ripening consists in changing the composition of the silver bromide grain towards an unknown, optimum concentration." He concludes, too, that it seems theoretically possible to make an almost infinitely fast plate having a very fine grain. Dr. R. Luther set forth the various arguments concerning the nature of the developable image, and J. Desalme reported on present notions concerning the theory of development. The latter considers that the electrolytic hypothesis affords a much better explanation of development than that based on a reduction by a purely chemical process, that is, that a developing solution contains an electrolyte and a depolariser suitable to the positive ions produced. This explains the non-equivalence of the alkalies if substituted in the proportion of their combining weights.

The difficulties of measuring the true opacity or obstructive power of photographic plates were described by F. F. Renwick, who stated that the apparent opacity of a negative under any given conditions is the algebraic sum of several variable properties. These he classifies as the simple obstructing power, the diffracting power of small particles and of the slightly rough surface of the film, the increase in transmitted light when the incident light falls obliquely on the surface, and the increase when the plate being measured is placed close to a reflecting surface if the difference between the readings with the negative so placed, and when the negative is removed, is taken as the opacity. He also criticised adversely the use of acetylene flames as light standards unless many stringent precautions are taken. The principles involved in attempting to measure the diffuse reflecting power of photographic plates were enumerated by $A$. Callier and $R$. von Camvenberghe, but they gave no practical details. Drs. Mees and Sheppard described various improvements in acetylene burners when used as secondary light standards, to meet objections that have been urged against earlier forms, and referred shortly to other standards. Dr. E. Goldberg described an apparatus that he has devised (made by Schmidt and Haensch, of Berlin) by means of which the characteristic curve of a plate can be obtained without the more or less tedious plotting generally done. From the group of papers dealing with these branches of the subject, it is clear that the measurement of the densities of photographic plates is a process still set about with difficulties and confusions, and that much work remains to be done in this direction.

Coming to the more technical branches of the subject, we find that a great many widely different matters were treated of. Prof. R. W. Wood described how to take photographs with infra-red and ultra-violet lights. For the infra-red he uses, as a screen, a very dense cobalt glass with either a saturated solution of potassium bichromate or a suitable red aniline dye, and, of course, a suitably red-sensitised plate. Under such conditions grass and trees in full sunshine appear snowy white and the sky as black as midnight. All shadows are very black, as there is practically no light from the sky to illuminate them. For the ultra-violet photographs, quartz lens were used coated with metallic silver to such an extent that a brilliantly lighted window was barely visible through them, and appeared of a deep violet colour. The light transmitted was of wave-lengths from 3100 to 3250 . When photographed under these conditions, certain white flowers (as phlox) and Chinese white (zinc oxide) appear as if absolutely black, but ordinary landscapes do not 
show points of much special interest. Prof. Wood suggests various possibly useful applications of such methods. Prof. R. Namias has examined prints toned with gold and platinum to ascertain the amount of precious metal entering into the finished print. C. W. Gamble described a method of determining the melting point of gelatine jellies. $\mathrm{He}$ uses capillary tubes, and notices when the concave meniscus changes to a flat surface.

A. and L. Lumière and A. Seyewetz classified and compared the various gelatine-hardening agents, and recommend the use of quinone and its sulphonic derivatives when the gelatine is on a rigid support, in preference to formalin, as the latter tends to contract the gelatine and detach it. They find that quinones in acid solution are serviceable for the reduction of photographic silver images, and that their action is comparable to that of ammonium persulphate in appearing to attack by preference the denser deposits. They suppose that the resulting hydroquinone tends to deposit silver, by reduction from the solution, on the surface, and so to prevent the loss of the thinner deposits.

A method for getting instantaneous exposures on autochrome plates was described by $\mathrm{Ch}$. Simmen. The plate is sensitised to red by bathing, and with a suitable compensation filter is eight times more sensitive than the untreated plate. N. S. Amstutz reported on recent progress in process work in the United States of America. We notice that Pavnetype has not yet come into general use; that collotype has not made much headway, in spite of the hopes of its adherents, presumably for lack of attention to climatic conditions; but illustrative telegraphy is taking its place as a practical method of transmitting pictures. W. F. Conper and G. A. Freak have compared nickel (or nickel-surfaced plates) as a substitute for copper for half-tone work, and find that ferric chloride acts on it (for etching) at something less than half the rate that it acts on copper.

Telephotography is the subject of a report by Captain Owen Wheeler; other than this, photographic optics was hardly represented. It will, of course, be understood that in this summary it has not been possible to refer to more than a comparatively few of the communications made to the congress.

\section{THE ORIGIN AND CIASSIFICATION OF} MAMMALS. ${ }^{1}$

A HEARTY welcome may be accorded to the work referred to below, which contains a well-elaborated and highly philosophical digest of the present state of our knowledge of the past history and relationships of the various groups of mainmals, and the inferences which may be legitimately drawn from such knowledge. The work owes its inception to the need for a brief outline of the history of the ordinal classification of mammals for use in Columbia University; but it was soon found inadvisable to limit its scope to this portion of the subject, and it consequently covers a much wider range. It retains, however, traces of its original limitation in consisting of two distinct parts, namely, an account of the typical stages in the history of the classification of mammals, and, secondly, of the genetic relations of the orders and a discussion of the origin of the class as a whole, with special reference to the problem of the auditory ossicles.

The, first part, although of great value to the student, may be passed over without further mention on this occasion, and attention concentrated on the second. Before proceeding to a brief survey of the latter, reference may be made to the author's endeavours to give a rational explanation of the meaning of each important feature with which he has to deal, and not to rest content with a mere catalogue of bare facts. Indeed, the adherence to mere facts on the part of so many of his predecessors has been, in the author s opinion, a fruitful source of our lack of progress in getting a real grasp of mammalian evolution, and he specially urges the need of an osteological treatise written from this newer point of view. It is added that the importance of osteology in the study of mammals cannot be overestimated, as the clue to the origin of the class and the 1 "The Orders of Mammals." By W. K. Gregory. Bull. Amer. Mus.
Nat. Hist., vol. xxvii., 19ro. Pp. 504.

NO. 2 I 29 , VOL. 84$]$ relationships of its constituent orders can be obtained from palacontology alone, which in this case is restricted to the osteology and dentition.

As regards the origin of mammals, Mr: Gregory adopts the view that the class is descended in all probability from that section of the anomodont reptiles which Dr. Broom has proposed to designate cynodonts, but which are more commonly included in the theriodonts, although not from any known member of the same. The features in which cynodonts approxinate to mammals on the one hand and to more ordinary reptiles on the other are carefully formulated. The difficult question of the fate of the reptilian quadrate and the homology of the mammalian malleus and incus is left to a great extent open, although the author seems inclined to favour the view that the incus reperesent: the quadrate and the body of the malleus the articular.

The second chapter of this part is devoted to the monotremes, which are regarded as undoubted mammals, with evident relationships to the marsupials, as is indeed indicated by their geographical distribution. Nevertheless, monotremes are taken to represent a subclass by themselves, while marsupials and placentals are brigaded together in a second group of equivalent value, and it is added that the divergence of the monotreme from the marsupio-placental stock must have taken place at a relatively early date. Within the same section as the marsupials are grouped, as a second and equivalent order, the Mesozoic iriconodonts, which cannot be regarded as true nursupials, and it is notewortlyy that the theory of the conversion of the triconodont into the tritubercular type of molar by means of torsion is now definitely abandoned. On the other hand, in view of Gidley's study of Ptilodus, the Multiluberculata are now re-admitted to the marsupial order, although the author will not allow that they are diprotodonts. The evidence of the Triassic Microlestes, supple. mented by that of the structure of the tecth themselves, indicates that the multitubcrculate molar is a far older type than the tritubercular, which is first known-in an incompletely developed condition-in the Middle Jurassic Imnhitherium.

The view that the carnivores of the Santa Cruz beds are not only marsupials, but likewisc members of the same family as the Tasmanian wolf, is definitely accepted, and it follows from this that there is no definite genetic relationship between creodonts and carnivorous marsupials. Indeed, the author considers each group to have been independently derived from small insectivorous and completely or partially arboreal Mesozoic forms, this being, if true, sufficient to indicate that the resemblance between the larger Tertiary forms is due to convergence. In opposition to some of his contemporaries, Mr. Gregory regards crcodonts as neariy related to the Insectivora (from which tupais and jumping-shrews are separated as a distinct order, Menotyphla), and likewise considers the latter to be more closely related to marsupials than is the case with any other placental group. On the other hand, he looks upon the palatal vacuities of Erinaceus as sccondary rather than marsupial features. The date of separation between Carnivora and Insectivora is considered to be pre-Tertiary, and it is left an open question whether the ancestors of the latter had their incisors extending along the sides of the jaw (instead of being restricted to the front) as in their modern representatives.

Only very brief reference can be made to some of the other orders, among which it is important to notice that the extinct zeuglodonts are included in the Cetacea. Perhaps the greatest changes in classification are proposed in the case of the ungulates, from which the Artiodactyla are removed to form a separate ordinal, and supraordinal, sroup, as the author believes they have no near relationship with Perissodactyla. On the other hand, the Ungulata are taken to include, not only elephants, hyraxes, perissodactyles, and the South American groups, which are brigaded as Notoungulata, but likewise sirenians. Much is to be said both for and against these proposed changes, but space does not admit of discussing the matter, and it must suffice to add that we find the Primates, with man at the head, forming part of a "superorder" in the middle of the class instead of standing at the head. Whether we accept all his views or not, there can be no question that in this volume $\mathrm{Mr}$. Gregory has accomplished a most valuable and important piece of work.

R. L. 